\title{
Myanmar monsoon drought variability inferred by tree rings over the past 300 years: linkages to ENSO
}

Rosanne D'Arrigo', J. Palmer ${ }^{2}$, C. Ummenhofer ${ }^{3}$, N.N. Kyaw ${ }^{4}$ and P. Krusic ${ }^{5}$

'Lamont-Doherty Earth Observatory (LDEO), Palisades, USA; rdd@ldeo.columbia.edu

${ }^{2}$ Gondwana Tree-Ring Laboratory, Canterbury, New Zealand; ${ }^{3}$ Woods Hole Oceanographic Institution, Woods Hole, USA; ${ }^{4}$ Forest Department,

Naypyidaw, Myanmar; ${ }^{5}$ Bert Bolin Centre for Climate Research, Sweden University, Stockholm, Sweden

A new tree-ring record of teak from Myanmar yields information about past tropical monsoon rainfall variability, including sustained drought conditions, and climatic effects of the El Niño-Southern Oscillation (ENSO), dating back nearly four centuries.

$\mathrm{E}^{\mathrm{x}}$ treme climatic conditions linked to the Asian monsoon and modulated by the ENSO system, such as droughts and floods, severely impact human populations. In 2008, Cyclone Nargis caused $>138,000$ fatalities and more than an estimated 10 billion US\$ in economic damage. However, our knowledge of monsoon climate and ENSO-related impacts remains limited, not the least due to sparse paleoclimatic information. Such information is especially scarce for Myanmar, which is directly impacted by the effects of the monsoon but where even instrumental climate records and related studies of monsoon climate dynamics are rare. Much of the country experiences pronounced wet and dry seasons linked to the seasonality of the monsoon. Myanmar rainfall correlates significantly with indices of ENSO and Indian monsoon rainfall (e.g. All India Summer Monsoon Rainfall and Core Indian Rainfall), although these relationships are spatially and seasonally variable and not very well understood. Myanmar's location in the transition zone between the South Asian and East Asian monsoon systems results in a particularly complex spatial pattern of precipitation variability.

\section{Asian Monsoon dendroclimatology}

Gleaning additional information on the long-term climate variability of Myanmar and greater monsoon Asia relies on records from natural or historical paleoclimatic archives. Tree rings are often ideal as they can yield precisely dated, annual time series, also referred to as "chronologies", dating back centuries to millennia. Studying tropical tree rings poses considerable difficulties because of the lack of pronounced seasons at low latitudes where monsoonal rainfall occurs, and the associated obstacles in identifying tree species that can be dated for dendrochronology. Nevertheless, much progress in chronology development has been made in recent years that now allows us to reconstruct past climate in tropical Asia from tree rings (e.g. Cook et al. 2010, Monsoon Asia Drought Atlas MADA; Buckley et al. 2007, 2010; Ummenhofer et al. 2013).

The MADA tree-ring dataset was analyzed for past changes in the Palmer Drought Severity Index (PDSI) and thus provided evidence for major droughts and wet events in Southeast Asia (e.g. Indonesia, Thailand, and Vietnam). However, in the case of Myanmar, tree-ring data coverage is still exceedingly sparse and represents a sizeable gap in paleoclimate information of monsoon Asia. Here we present a new record for Myanmar that can be incorporated into the MADA network.

\section{Myanmar teak}

Teak (Tectona grandis) is one of the tree species that has been used most successfully

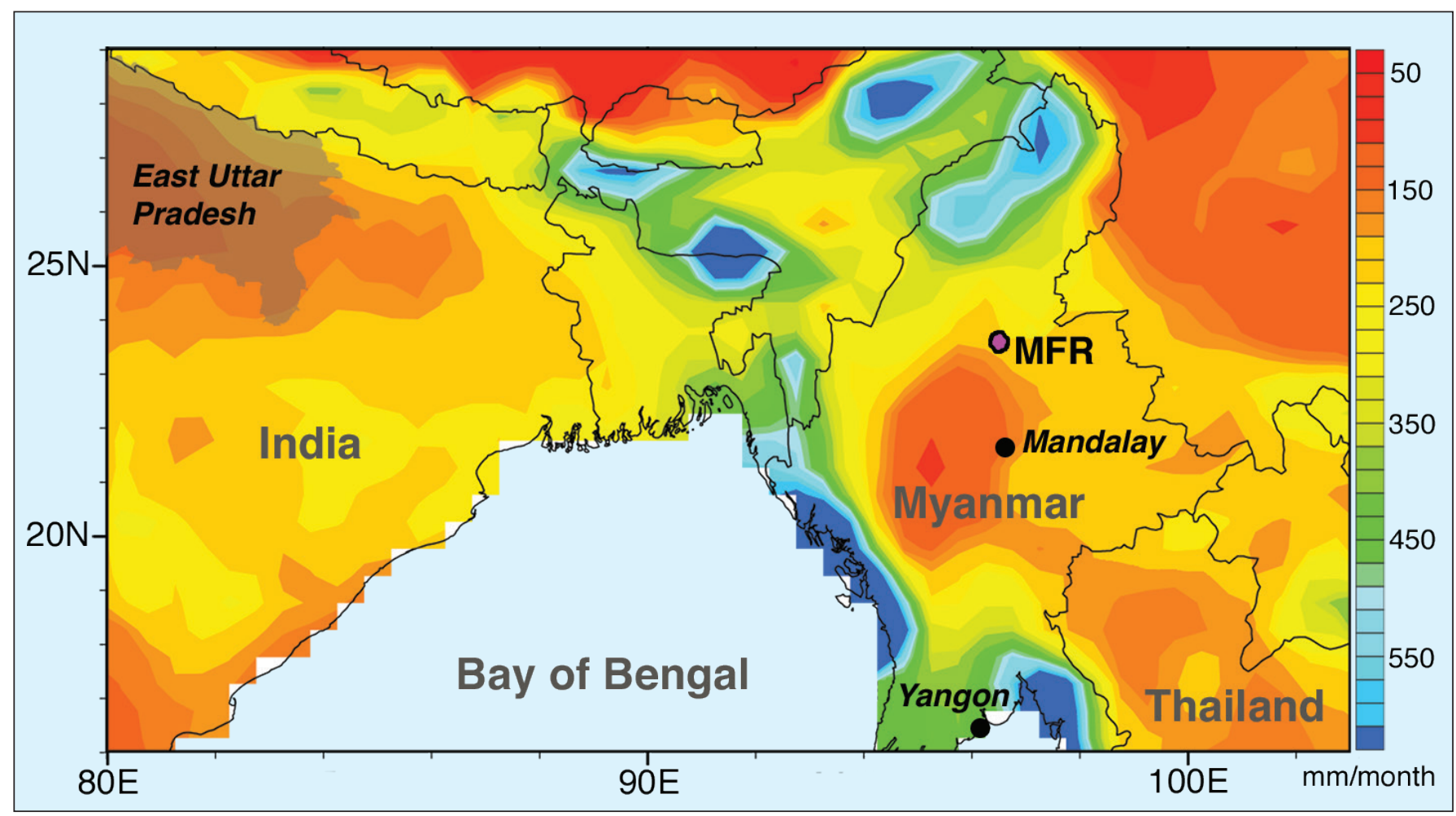

Figure 1: Map of Myanmar and adjacent southern monsoon Asia. Pink dot is Maingtha Forest Reserve (MFR) teak tree-ring site north of Mandalay. Background shows monthly Global Precipitation Climatology Centre rainfall data for the period 1951-2007, averaged for May-October when the majority of Myanmar annual rainfall occurs. The figure shows the lower mean rainfall in central Myanmar (modified from D'Arrigo et al. 2011). 


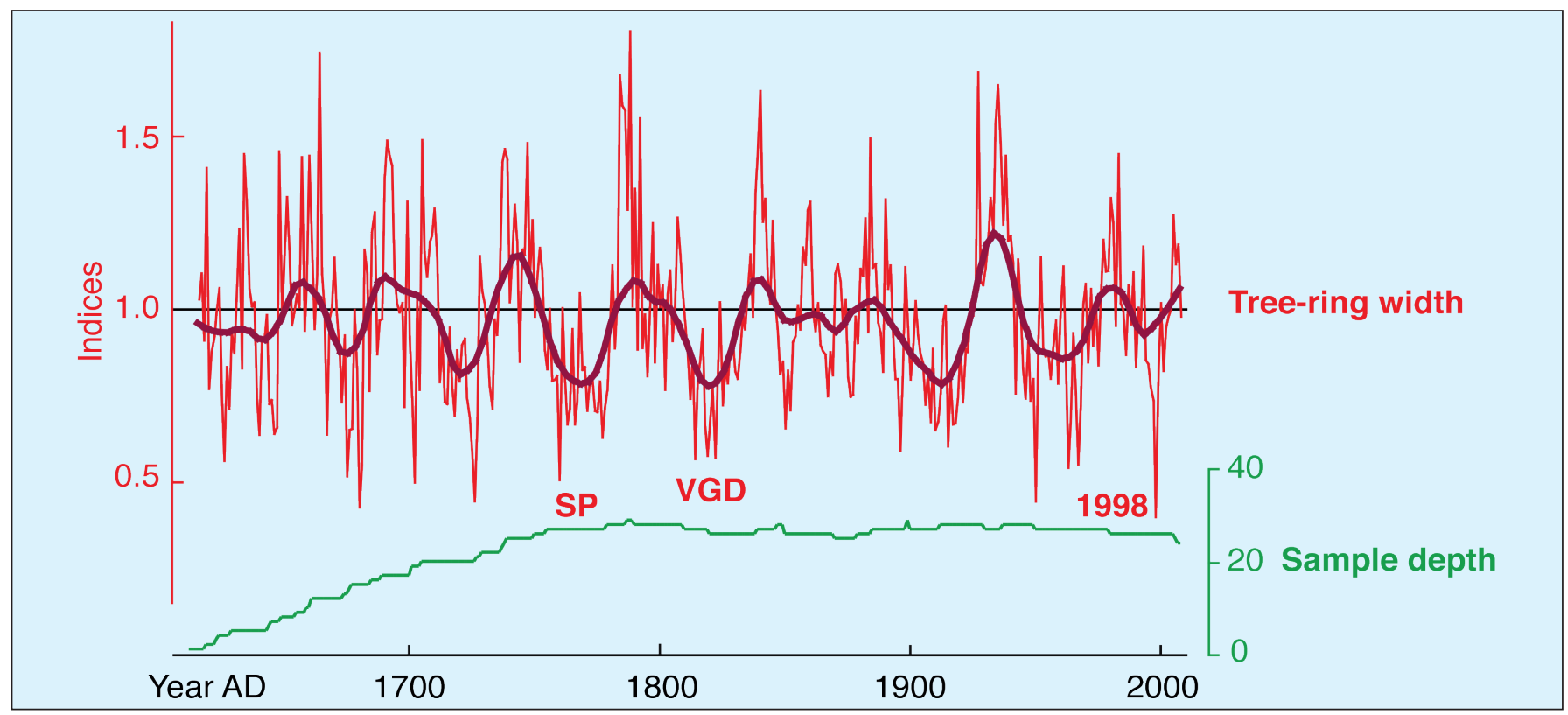

Figure 2: Tree-ring width chronology of teak (in dimensionless indices or values) for central Myanmar, spanning 1613-2009 AD, with sample depth (number of individual tree samples). Sample depth is near its peak over much of the chronology, gradually declining prior to the middle 1700s. Plot labels time of Strange Parallels (SP) drought in the 1700 s (Buckley et al. 2007, 2010), the late Victorian Great Drought (VGD), and narrow ring at time of 1997-98 "El Niño of the Century" (modified from D'Arrigo et al. 2011).

for tropical dendroclimatology. It is endemic to Myanmar, but due to its great commercial value it is now rapidly disappearing across the country. Our new ring width chronology of teak for the Maingtha Forest Reserve is one of the first high-resolution proxy records that were developed for Myanmar (Figs. 1 and 2; D'Arrigo et al. 2012). It is based on 38 individual series from 20 living trees and spans the years 1613-2009 AD. Teak growth at the site is positively correlated with rainfall and PDSI variability over Myanmar, during and prior to the May-September wet monsoon season. Accordingly, the Maingtha Forest Reserve record reveals past variability of Myanmar hydroclimate.

Monthly correlations between the Myanmar teak ring-width chronology (Fig. 2) and instrumental PDSI (1950-2003 AD) were computed for the region overlapping our teak site $\left(15-25^{\circ} \mathrm{N}, 95-105^{\circ} \mathrm{E}\right)$, for the period, from the year prior to the current year of radial growth to the current year. Statistically significant (95\% level), positive correlations were found for the months concurrent and just prior to the wet monsoon season, from around April to August. Correlations with PDSI are strongest when averaged over May and June $(r=0.32, n=54)$, reflecting the importance of moisture availability for teak growth in central Myanmar around the time of monsoon onset. Comparison with local monthly station rainfall records (e.g. for Mandalay and Yangon) further confirms that teak growth in central Myanmar is controlled by moisture availability.

This teak record also correlates significantly with larger-scale climate indices, including those for core Indian rainfall and
ENSO. With the IITM All-India monsoon rainfall index, correlation for May-Jun is $r=0.36$ $(p<0.01, n=57)$. Correlations are stronger using the core northeast Indian monsoon rainfall index, which represents the region of India opposite the Bay of Bengal from Myanmar $\left(23^{\circ} \mathrm{N}, 76^{\circ} \mathrm{E}\right)$. Averaged over JanJun (1950-2006), the correlation is $r=0.46$ $(p<0.001)$. For East Uttar Pradesh, a subdivision of this core region, the correlation is 0.47 since 1950 (Jan-Jul, $\mathrm{p}<0.001, \mathrm{n}=57$ ); and $r=0.29$ over the maximum common period ( $\left.p<0.001, n=136 ; 26^{\circ} \mathrm{N}, 82^{\circ} \mathrm{E}\right)$.

The Myanmar teak chronology correlates negatively with Niño-3 SST (Jul-Aug, $r=-0.27, p<0.05, n=60)$. This is consistent with the tendency for positive Niño-3 SSTs, as during El Niño warm events, to be linked to drought conditions and decreased teak growth over southeast Asia, due to the eastward migration of the Walker circulation. Notably, Myanmar teak growth in the year 1999, following the so-called "El Niño of the Century" of 1997-1998, is the lowest of any year on record (Fig. 2). The year 1998 also shows the lowest annual rainfall value for central Myanmar. Myanmar teak growth is also below average during the Strange Parallels drought (Fig. 2) found across southeast Asia in the 1700s. The late Victorian Great Drought was associated with a major ENSO warm episode (1876 to 1878) and is perhaps the most spatially pervasive and severe drought in the MADA tree-ring data set for monsoon Asia (Cook et al. 2012; Buckley et al. 2007, 2010).

\section{The potential of the new Myanmar record}

Our new teak tree-ring width chronology from central Myanmar, one of the first paleoclimate records published for this country, is significantly and positively correlated with local and regional precipitation as well as with larger scale indices of Indian monsoon core rainfall, particularly over northeastern India. The Myanmar teak records also correlate negatively with Niño-3 SST, consistent with the tendency for El Niño warm events to be linked to drought over Southeast Asia, as they were following the pronounced 19971998 warm event. Thus, this teak record reflects not only local conditions, but also the large-scale strength of the circulation of the Asian monsoon-ENSO system. The timing of the inferred drought conditions coincides with megadroughts identified elsewhere in southeastern Asia, including Thailand and Vietnam (Buckley et al. 2007, 2010), and which are attributed to variability in the tropical Indo-Pacific climate system and the Intertropical Convergence Zone. Overall, our results indicate much potential for generating reconstructions of monsoon climate dynamics for Myanmar and the wider region from tree-ring data.

\section{Note}

MADA dataset available online at the NOAA Paleoclimatology website, International TreeRing Databank (ITRDB).

\section{References}

Buckley B et al. (2010) PNAS 107: 6748-6752

Buckley B et al. (2007) Climate Dynamics 29: 63-71

Cook Eet al. (2010) Science 328: 486-489

D'Arrigo R et al. (2011) Geophysical Research Letters 38, doi:10.1029/2011GL049927

Ummenhofer C et al. (2013) Climate Dynamics 40: 1319-1334 